\title{
Tracking Down Nonresponsive Cortical Neurons in Cochlear Implant Stimulation
}

\section{(D) Charlotte Amalie Navntoft}

DOI:http://dx.doi.org/10.1523/ENEURO.0095-17.2017

Department of Biomedicine, Basel University, Basel, 4056, Switzerland

\section{Visual Abstract}

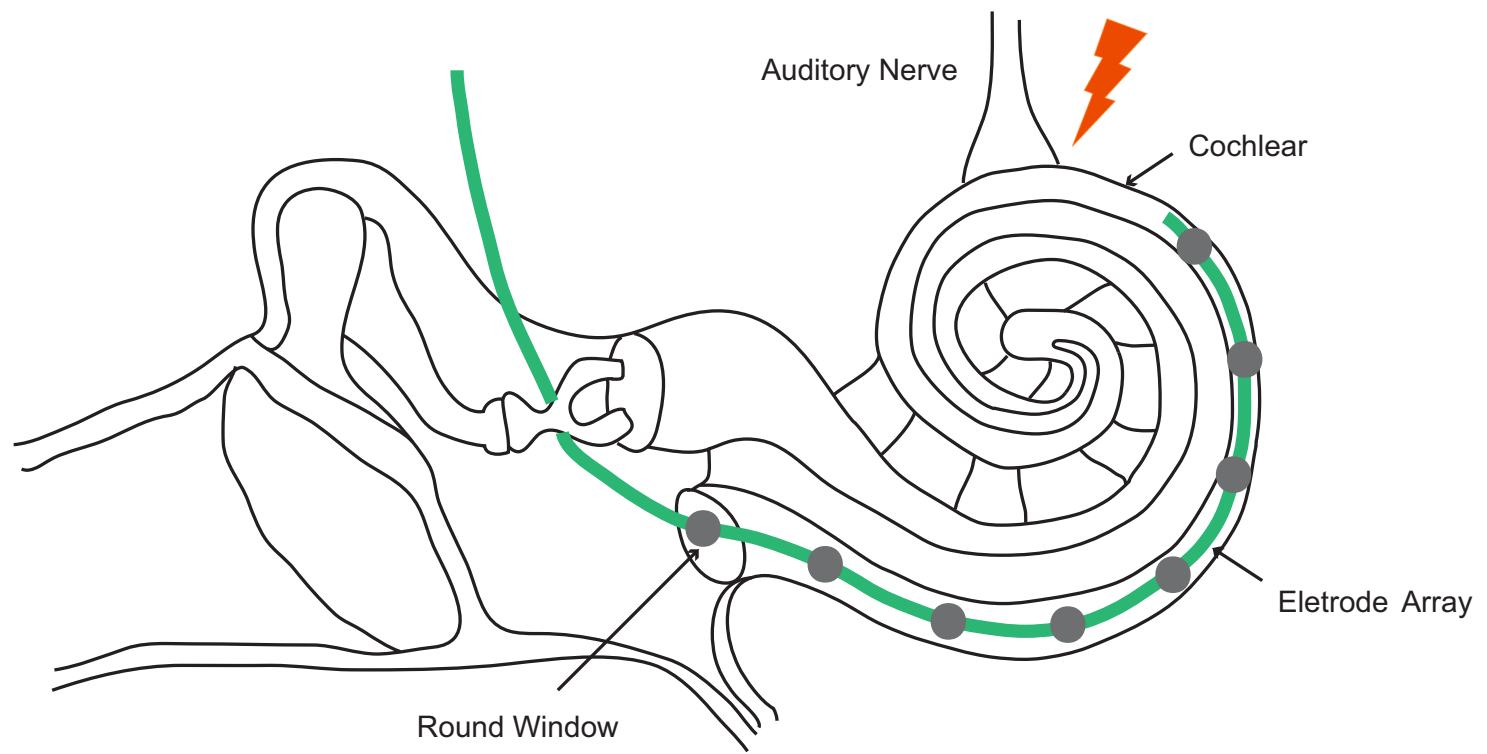

Key words: Auditory cortex; cochlear implants; interneurons; marmoset; sideband inhibition

\section{Significance Statement}

The cochlear implant $(\mathrm{Cl})$ can restore a sense of hearing to deaf people. Although it works well in quiet situations, most $\mathrm{Cl}$ users still struggle to follow conversations in noisy environments and perceive music. One challenge in $\mathrm{Cl}$ stimulation is that the brain must resolve and interpret the signal to generate meaningful and goal-oriented hearing. How efficient this process is and how the underlying neuronal circuits respond, or fail to respond, to such input compared with normally transmitted sound is essentially unknown. Understanding these central auditory mechanisms is crucial for the further development of Cls. In a recent study published in The Journal of Neuroscience, Johnson et al. (2016) investigated how Cl stimulation engages the auditory cortex in awake marmosets. There were two main findings: first, Cls are surprisingly inefficient in activating cortical neurons that normally respond to sound; second, Cl-responsive neurons are functionally different from non-Cl-responsive neurons. Here, we discuss the results and hypothesize how inhibition could be involved the brain's response to Cls. 
Sound travels from its source to the ear, and further on eventually to the brain, through a chain of biological mechanisms that convert vibrations in the air into nerve impulses. In deaf people, the link between sensory hair cells and the auditory nerve in the cochlear is often broken (or the terminals of the auditory nerve are simply gone), and the auditory input therefore never reaches the brain. Cochlear implants (Cls) bypass this missing link by directly stimulating the auditory nerve. To date, this approach has restored hearing sensation to $>300,000$ severely and profoundly deaf people.

Present-day design of Cls is based on a bottom-up approach in which the goal is to reproduce normal patterns of neural activity at the auditory periphery. In a recent study published in The Journal of Neuroscience, Johnson et al. (2016) used another way of thinking about $\mathrm{Cl}$ design that includes mechanisms from the central auditory system, and not only its periphery. In such a top-down approach, one asks what input the central auditory system needs to perform optimally in a given situation (Wilson et al., 2011).

The common marmoset (Callithrix jacchus) is a valuable model of how the human brain processes auditory information: it is a highly vocal, communicative, and social nonhuman primate, and its hearing range and organization of the auditory cortex (AC) are similar to those of humans (de la Mothe et al., 2006; Osmanski and Wang, 2011). Furthermore, the use marmosets makes possible the determination of single-neuron responsiveness, which is extremely difficult or impossible to obtain in humans.

Johnson et al. used a novel unilateral $\mathrm{Cl}$ model, implanting an eight-electrode array in one ear of the marmoset and leaving the other ear intact. Taking advantage of the binaural properties of AC-neurons in one hemisphere are excited by inputs from both ears-the authors precisely located the primary auditory cortex (A1) and characterized the acoustic features and selectivity of $\mathrm{A} 1$ neurons to $\mathrm{Cl}$ stimulation (Fig. 1A, $B$ ).

First, the authors investigated how efficient a $\mathrm{Cl}$ is in transmitting information to the AC compared with acoustic stimuli. They recorded 1408 single neurons from the $A C$ and classified them as either acoustic-driven (the neuron responded to tones or bandpass noise) or $\mathrm{Cl}$ driven (the neuron responded to electric stimulation of the implant). It is important to highlight that acoustic and $\mathrm{Cl}$ stimulation are two different quantities (Wilson and Dorman, 2009), and the authors therefore carefully optimized stimuli parameters to match them as well as possible. One

Received March 22, 2017; accepted June 15, 2017; First published June 22, 2017.

Acknowledgments: I thank Eva Meier Carlsen for critically reading this manuscript and providing helpful comments.

Correspondence should be addressed to Charlotte Amalie Navntoft, Department of Biomedicine, Basel University, Klingelbergstrasse 50-70, Room 7014, 4056 Basel, Switzerland. E-mail: charlotte.navntoft@unibas.ch.

DOI:http://dx.doi.org/10.1523/ENEURO.0095-17.2017

Copyright @ 2017 Navntoft

This is an open-access article distributed under the terms of the Creative Commons Attribution 4.0 International license, which permits unrestricted use, distribution and reproduction in any medium provided that the original work is properly attributed. striking finding of the work is that $\mathrm{Cl}$ stimulation was surprisingly inefficient at activating as many neurons as comparable acoustic stimulation. Why are some neurons, and not others, activated by a Cl?

One possible explanation is related to the differences between contralateral and ipsilateral stimulation, with contralateral stimulation typically being much more effective and precise (Lui et al., 2015). Because their novel unilateral model allowed for testing each neuron's response to both acoustic and Cl stimulation, Johnson et al. could compare acoustic properties of nonresponsive and $\mathrm{Cl}$-driven cells. The assumed binaurality is a limitation of the paper. It may have been difficult to "functionally localize" responsive neurons, via acoustic stimulation, in the hemisphere contralateral to the implant because the response to ipsilateral acoustic stimulation is different. To address this issue, the authors could have recorded the cortical response first to contralateral acoustic stimulation and then to contralateral $\mathrm{Cl}$ stimulation after $\mathrm{Cl}$ insertion in the same ear.

A second possible explanation is that the $\mathrm{Cl}$ has been activated only with a standard stimulation protocol and not a test battery of additional $\mathrm{Cl}$ pulse variables (e.g., different pulse wave form shapes, pulse durations, pulse stimulation rates, amplitude modulation), which potentially could engage neurons in a more similar way (higher number of activated neurons, more focused response in the tonotopic map, higher firing rate, etc.). A third possibility is lack of cortical adaptation to $\mathrm{Cl}$ stimulation, discussed below.

The response of a neuron to pure tones of varying frequency and level, known as its frequency response area (FRA), is a fundamental receptive field measure in the auditory system (Sutter et al., 1999). Neurons with socalled V-shaped FRAs respond to more frequencies with increasing sound levels, whereas O-shaped FRAs are narrowly tuned to sound frequency and level (Sadagopan and Wang, 2008). That $\mathrm{Cl}$ stimulation mainly engaged neurons with V-shaped FRAs while nonresponsive cells typically had O-shaped FRAs supports the authors' argument that $\mathrm{Cl}$ stimulation differs in some fundamental ways from the stimulation that results from actual sounds (Johnson et al., 2016).

Why do neurons with small and selective receptive fields not respond to $\mathrm{Cl}$ stimulation? Are they simply not activated, or are they suppressed? It is well established that the interaction between inhibition and excitation plays a crucial role in shaping and refining the brain's representation of sensory stimulus attributes (Wehr and Zador, 2005). Nonresponsive cells were mainly located in upper cortical layers and $\mathrm{Cl}$-responsive cells in middle thalamo-recipient layers, suggesting that the $\mathrm{Cl}$ signal is received by cortical structures but does not progress to further intracortical processing. In A1, so-called sideband inhibition helps to sharpen the tuning of local neuronal responses and appears as suppression of $A 1$ neurons by off-frequency components (Sutter et al., 1999; Wang et al., 2000; de la Rocha et al., 2008). A big issue with $\mathrm{Cl}$ stimulation is that the applied current spreads over a wide area, stimulating a large neuronal population (Lands- 

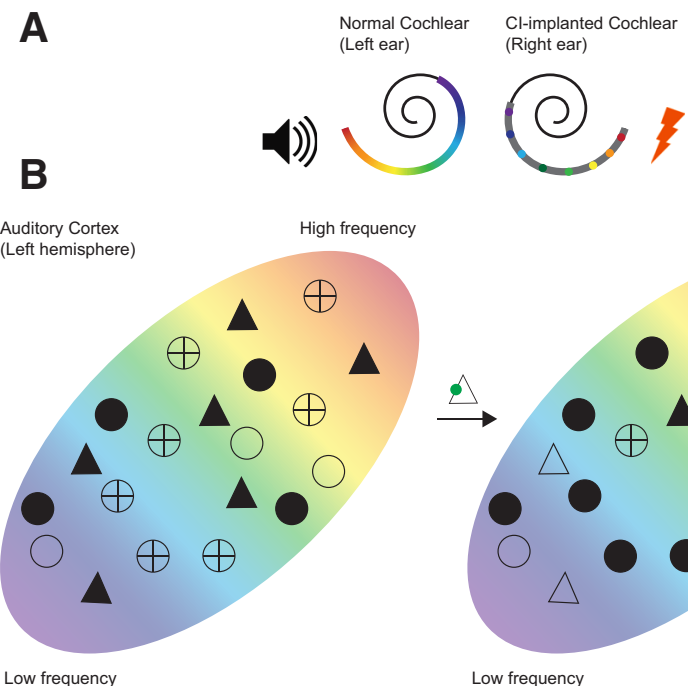

\section{c}
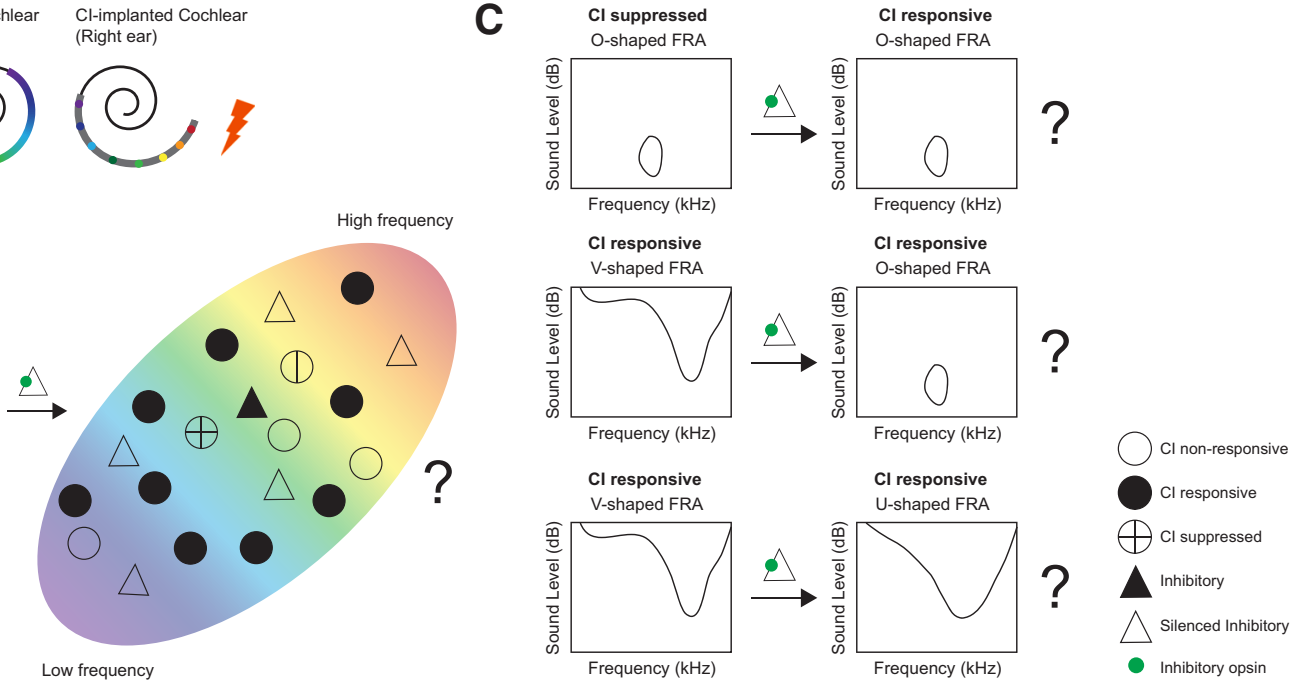

Figure 1. A, The setup used in Johnson et al., 2016. A Cl implant with eight electrodes is implanted in the right ear, and the left ear is left acoustically intact. The perception of different frequencies is elicited by stimulating different electrodes along the tonotopic axis in the cochlea (color gradient). This strategy allows Johnson et al. to measure the response of single neurons in the left auditory cortex to both acoustic and $\mathrm{Cl}$ stimulation in an awake marmoset, and thereby to examine the characteristics of neurons that respond, or fail to respond, to $\mathrm{Cl}$ stimulation. Acoustic and $\mathrm{Cl}$ stimuli were matched whenever possible. For $\mathrm{Cl}$ stimulation, the response of a neuron is tested across different electrode positions and at multiple current levels, and analogously for acoustic stimulation, across a range of frequencies and at multiple sound levels. The $\mathrm{Cl}$ electrode/frequency producing the significantly largest firing rate response is defined as the best electrode or best frequency of the neuron, for $\mathrm{Cl}$ and acoustic stimulation, respectively. The receptive field of a neuron is described by electrode/frequency tuning curves across all current/sound levels. B, Hypothesis: interneurons, particularly $\mathrm{PV}$ interneurons, are important for effective cortical response to $\mathrm{Cl}$ stimulation. Left, $\mathrm{Cl}$ stimulation is surprisingly inefficient in activating A1 neurons (black circles) because many neurons are suppressed (crossed circle) by inhibitory interneurons (filled triangles). Right, decreasing inhibitory GABAergic interneuron activity using either optogenetics or pharmacology will increase the effectiveness of $\mathrm{Cl}$ stimulation, and in particular, likely yield more O-shaped neuron activity either from previously suppressed (top) or evolved from V-shaped neurons (middle; see text). However, decreased GABAergic inhibition would likely come at the cost of broader V-shape tuning in already $\mathrm{Cl}$-responsive cells (bottom). Filled circle, $\mathrm{Cl}$ responsive neuron; open circle, $\mathrm{Cl}$ nonresponsive neuron; crossed circle, suppressed neuron; filled triangle, active inhibitory neuron; open triangle, inactivated inhibitory cell; green circle, inhibitory opsin or pharmacological blockage.

berger et al., 2012), so the authors proposed that this spread activates an off-frequency component suppressive to neurons. Using broadband acoustic noise to mimic the broad $\mathrm{Cl}$ stimulation and a two-tone suppression protocol to probe sideband inhibition, they found that $\mathrm{Cl}$ nonresponsive neurons were also suppressed by broadband stimuli and more easily in the two-tone protocol than in Cl-only driven cells. Taken together, the results suggest that the widespread current after $\mathrm{Cl}$ stimulation activates neighboring off-frequency components that eventually suppress neuronal response to the incoming signal.

These results provide valuable insight into how $\mathrm{Cl}$ only partially engages the brain at the level of single neurons. Below, I place the findings into perspective and propose future experiments.

The finding that $\mathrm{Cl}$-mediated inhibition overwhelms excitation leaves many questions unanswered. Is this misbalance related to the strength of-or the timing between-excitation and inhibition? Which cell types and circuits are involved? Will less inhibition improve efficiency and selectivity of $\mathrm{Cl}$ stimulation, and eventually improve perception of $\mathrm{Cl}$ input?

To address the first question, one could look at the temporal dynamics of $\mathrm{O}$ - and $\mathrm{V}$-unit population responses on Cl stimulation as in Sadagopan and Wang (2010). That study examined how FRA shape changes over the duration of the response to played sound using populationaverage FRAs in small time bins. In addition to the welldocumented short-latency sideband suppression, they uncovered long-latency suppressions caused by single-tone stimulation. Interestingly, such long-latency suppressions also included monotonically increasing suppression with sound level both on-best frequency (BF) and off-BF. As the $\mathrm{Cl}$ mainly activated V-unit neurons with monotonic acoustic rate-level functions, this suppressive effect could contribute to the lack of $\mathrm{Cl}$ efficiency. Sadagopan and Wang (2010) also observed that over time a V-unit response evolved to an $\mathrm{O}$-unit-like response. Further analysis of the present data could therefore investigate whether $\mathrm{Cl}$ stimulation might fail to promote this process.

In the AC, synaptic inhibition is known to be involved in shaping receptive fields, controlling gain, and promoting temporal precision (Moore and Wehr, 2013; Aizenberg et al., 2015). The overall inhibitory tone is orchestrated by locally acting GABAergic interneurons. The most common types are parvalbumin-positive interneurons (PVs) that target the pyramidal cell bodies and gate feedforward thalamocortical auditory output of layer III/V neurons (Hamilton et al., 2013). In particular, PV activity is thought to be crucial for intensity tuning and to contribute to 
sideband inhibition and response timing (Moore and Wehr, 2013; Aizenberg et al., 2015). We therefore hypothesize that PV interneurons might play key roles in the observed inefficient cortical response to Cls. This hypothesis can be explored optogenetically via fast and efficient control of targeted cell types and, importantly, the opportunity to probe causal relations between various actors and actions of interest. A chronic optogenetic model has recently been developed in marmosets (MacDougall et al., 2016), and viral targeting of interneurons in marmosets is in its early phases (Dimidschstein et al., 2016). In the near future, it should be possible to optogenetically manipulate $\mathrm{PV}$ activity in $\mathrm{AC}$ while recording in $\mathrm{AC}$ of a Cl-implanted animal (Fig. 1). If $P V$ interneurons contribute to the lack of $\mathrm{Cl}$ response, inhibiting PV interneurons should increase the effectiveness of $\mathrm{Cl}$ stimulation and, in particular, might yield more O-unit activity either previously suppressed or evolved from V-shaped neurons. Until such an experiment is feasible, blocking all interneurons pharmacologically (GABAergic inhibitor) on $\mathrm{Cl}$ stimulation in awake marmosets could be an interesting first step in understanding the role of interneurons (not just PV) in A1. Nonetheless, decreased GABAergic inhibition would likely come at the cost of broader V-shape tuning in already $\mathrm{Cl}$-responsive cells, as previously reported (Wang et al., 2000). Indeed, a finely tuned balance between inhibition and excitation is needed to produce an optimal cortical response after $\mathrm{Cl}$ stimulation.

Hearing with a $\mathrm{Cl}$ takes time and practice, because the auditory system must adapt to reinterpret the new auditory input as meaningful sound (Fallon et al., 2008; Kral and Sharma, 2012). Therefore, an important caveat of the work by Johnson et al. (2016) is that although recordings were made up to $14 \mathrm{mo}$ after $\mathrm{Cl}$ implantation, animals received only passive stimulation during the experimental sessions and not during engagement in a task, communication with conspecifics, or any other interaction with the surrounding environment. The results might thus relate to mechanisms in a recently implanted $\mathrm{Cl}$ user, before any experience and behavioral-dependent plasticity takes place, rather than in an experienced $\mathrm{Cl}$ user whose brain has adapted to make sense of $\mathrm{Cl}$ stimulation.

The authors found that neurons sharply tuned to frequency and sound level (O-shaped FRAs) are poorly activated by $\mathrm{Cl}$ stimulation, but whether this is a result of (1) cortical Cl-evoked response or (2) lack of plastic changes is difficult to tell. In favor of the first statement, many Cl users face challenges hearing in dynamic and noisy environments, which is partially due to limited dynamic range (5-15 dB compared with 0-120 dB in normal hearing) and a poor ability to discriminate steps in amplitude of a sound (Moore, 2003; Wilson et al., 2011). As these phenomena require fine and robust representation of sound level, it is likely that a general lack of O-unit response could underlie these perceptual limitations.

On the other hand, supporting the second statement, Polley et al. (2006) have shown that behavioral training in rats caused overrepresentation of the target-specific sound level in the AC (Polley et al., 2006), and plasticity is known to reorganize receptive fields in the AC (Froemke, 2015). Taken together, these data suggest that the marmoset $A C$ in the study by Johnson et al. (2016) has a history of experience with real sounds but not the kind of stimulation produced by Cls. Future experiments using the $\mathrm{Cl}$ marmoset model could test the hypothesis that $\mathrm{O}$-units are important for $\mathrm{Cl}$ performance in noisy surroundings. This approach might also reveal whether general experience and behavioral testing with chronic $\mathrm{Cl}$ stimulation can engage more $\mathrm{O}$-units, and if so, how this would impact perception of $\mathrm{Cl}$ stimulation. Finally, using the top-down approach described by Wilson et al. (2011), future experiments could use a test battery of other $\mathrm{Cl}$ parameters (e.g., different carrier rate, asymmetric or ramped pulse shapes, coding intensity via duration instead of amplitude, amplitude modulation) to precisely target and engage more O-units.

Altogether, Johnson et al. (2016) provide solid insight into how the brain responds, or fails to respond, to $\mathrm{Cl}$ stimulation. The findings will provide crucial guidance for the development of next-generation Cls that target neuronal circuits normally engaged by sound and eventually have potential to improve the outcome of Cls.

\section{References}

Aizenberg M, Mwilambwe-Tshilobo L, Briguglio JJ, Natan RG, Geffen MN (2015) Bidirectional regulation of inate and learned behaviors that rely on frequency discrimination by cortical inhibitory neurons. PLoS Biol 13:e1002308. CrossRef Medline

de la Mothe L, Blumell S, Kajikawa Y, Hackett T (2006) Cortical connections of the auditory cortex in marmoset monkeys: core and medial belt regions. J Comp Neur 27-71. CrossRef

de la Rocha J, Marchetti C, Schiff M, Reyes AD (2008) Linking the response properties of cells in auditory cortex with network architecture: cotuning versus lateral inhibition. J Neurosci 28:91519163. CrossRef Medline

Dimidschstein J, et al. (2016) A viral strategy for targeting and manipulating interneurons across vertebrate species. Nat Neurosci 19:1743-1749. CrossRef

Fallon JB, Irvine DR, Shepherd RK (2008) Cochlear implants and brain plasticity. Hearing Res 238:10-17. CrossRef

Froemke RC (2015) Plasticity of cortical excitatory-inhibitory balance. Annu Rev Neurosci 38:195-219. CrossRef Medline

Hamilton LS, Sohl-Dickstein J, Huth AG, Carels VM, Deisseroth K, Bao S (2013) Optogenetic activation of an inhibitory network enhances feedforward functional connectivity in auditory cortex. Neuron 80:1066-1076. CrossRef Medline

Johnson LA, Della Santina CC, Wang X (2016) Selective neuronal activation by cochlear implant stimulation in auditory cortex of awake primate. J Neurosci 36:12468-12484. CrossRef Medline

Kral A, Sharma A (2012) Developmental neuroplasticity after cochlear implantation. Trends Neurosci 35:111-122. CrossRef Medline

Landsberger DM, Padilla M, Srinivasan AG (2012) Reducing current spread using current focusing in cochlear implant users. Hear Res 284:16-24. CrossRef Medline

Lui LL, Mokri Y, Reser DH, Rosa MG, Rajan R (2015) Responses of neurons in the marmoset primary auditory cortex to interaural level differences: comparison of pure tones and vocalizations. Front Neurosci 9:132. CrossRef Medline

MacDougall M, Nummela SU, Coop S, Disney A, Mitchell JF, Miller CT (2016) Optogenetic manipulation of neural circuits in awake marmosets. J Neurophysiol 116:1286-1294. CrossRef Medline 
Moore AK, Wehr M (2013) Parvalbumin-expressing inhibitory interneurons in auditory cortex are well-tuned for frequency. J Neurosci 33:13713-13723. CrossRef Medline

Moore BC (2003) Coding of sounds in the auditory system and its relevance to signal processing and coding in cochlear implants. Otol Neurotol 24:243-254. Medline

Osmanski M, Wang X (2011) Measurement of absolute auditory thresholds in the common marmoset (Callithrix jacchus). Hear Res 277:127-133. CrossRef

Polley DB, Steinberg EE, Merzenich MM (2006) Perceptual learning directs auditory cortical map reorganization through top-down influences. J Neurosci 26:4970-4982. CrossRef Medline

Sadagopan S, Wang X (2008) Level invariant representation of sounds by populations of neurons in primary auditory cortex. J Neurosci 28:3415-3426. CrossRef Medline

Sadagopan S, Wang X (2010) Contribution of inhibition to stimulus selectivity in primary auditory cortex of awake primates. J Neurosci 30:7314-7325. CrossRef Medline
Sutter M, Schreiner C, McLean M, O'connor K, Loftus W (1999) Organization of inhibitory frequency receptive fields in cat primary auditory cortex. J Neurophysiol 82:2358-2371. Medline

Wang J, Caspary D, Salvi RJ (2000) GABA-A antagonist causes dramatic expansion of tuning in primary auditory cortex. Neuroreport 285:95-98.

Wehr M, Zador AM (2005) Synaptic mechanisms of forward suppression in rat auditory cortex. Neuron 47:437-445. CrossRef Medline

Wilson B, Dorman M. (2009) The design of cochlear implants. In: Niparko J, Kirk K, Mellon N, Robbins A, Tucci D, Wilson B, editors. Cochlear Implants: Principles and Practices. Philadelphia: Lippincott Williams and Wilkins, 95-135.

Wilson BS, Dorman MF, Woldorff MG, Tucci DL (2011) Cochlear implants matching the prosthesis to the brain and facilitating desired plastic changes in brain function. Prog Brain Res 194:117129. CrossRef Medline 